incidence is higher along the western seaboard than on the east coast, and in San Francisco in $196927 \%$ of strains required $0.5 \mathrm{unit} / \mathrm{ml}$ or more for inhibition.

Many of the strains which are insensitive to penicillin also show diminished sensitivity to other antibiotics. This was first seen with streptomycin, and led to its abandonment. The same situation appears to be developing with tetracycline, at present widely used as an alternative to penicillin. O. P. Arya and I. Phillips ${ }^{3}$ found only two of their Ugandan strains which were insensitive to penicillin to be sensitive to $0.5 \mu \mathrm{g} / \mathrm{ml}$ tetracycline. J. B. Lucas ${ }^{1}$ classed $42 \%$ of 627 American strains as resistant to tetracycline, including 85 out of 88 which were insensitive to penicillin.

Though the incidence of antibiotic resistance among gonococci seems to have remained static here for some years, experience from elsewhere suggests that the reprieve may be only temporary and that the wider dissemination of strains of multiple resistance may be expected. Can we do anything to prevent or delay this? Given in a large enough dose, penicillin is still very effective. A single injection of 4 to 5 megaunits with $2 \mathrm{~g}$ probenecid to delay excretion gave only $1 \%$ failures in trials reported by G. A. Olsen and G. Lomholt ${ }^{4}$ and by R. C. F. Gray and his colleagues. 5 The former trial was in Greenland, a relatively closed community, and the authors noted a diminution in the proportion of strains insensitive to penicillin from $54 \%$ to $19 \%$ during the latter half of their study. This suggests that effective treatment, if widely used, may reverse the trend towards resistance. But the dosage of penicillin used in these trials is about the maximum possible for a single injection.

Favourable results with ampicillin given by mouth have been reported by G. Eriksson ${ }^{6}$ in trials on over 3,800 patients in Sweden. Two doses of $1 \mathrm{~g}$ given five hours apart or a single dose of $2 \mathrm{~g}$ given with $2 \mathrm{~g}$ probenecid gave only about 2 to $3 \%$ failures, a rate comparable to that with a single dose of $2 \cdot 2$ megaunits penicillin. A single dose of $2 \mathrm{~g}$ ampicillin alone was less effective. About a quarter of the gonococci isolated during these trials had reduced sensitivity to penicillin. G. W. Csonka and G. J. Knight ${ }^{7}$ and B. R. T. Carroll and C. S. Nicol ${ }^{8}$ have had encouraging results with trimethoprim-sulphonamide mixtures given over five days. Of more recent antibiotics doxycycline and rifampicin have been found effective against the gonococcus. The latter has the advantage of lacking treponemocidal activity, but in view of its potential value in tuberculosis its use for gonorrhoea seems inadvisable.

Effective means of treatment of gonorrhoea are available, but they must be proved to have been effective in the individual patient. The importance of the proper clinical and bacteriological control of the results of treatment must be emphasized. Here sensitivity tests to antibiotics have an important place. Failure in the male is usually obvious, but in a few cases the signs of persistence may be minimal and are detected only by careful examination. ${ }^{9}$ In the female the disease is more often than not asymptomatic, and repeated clinical and bacteriological tests are essential to establish that cure has been achieved. The management of gonorrhoea is not just "a shot of penicillin." It should be undertaken only where adequate facilities for investigation are available.

1 Lucas, J. B., Southern Medical Bulletin, 1971, 59, No. 2, 22.

2 Lynn, R., et al., British fournal of Venereal Diseases, 1970, 46, 404.

3 Arya, O. P., and Phillips, I., British fournal of Venereal Diseases, 1970, 46, 149.

4 Olsen, G. A., and Lomholt, G., British fournal of Venereal Diseases, $1969,45,144$.
5 Gray, R. C. F., Phillips, I., and Nicol, C. S., British fournal of Venereal Diseases, 1970, 46, 401 .

6 Eriksson, G., Acta dermato-venereologica, 1970, 50, 451, 461.

7 Csonka, G. W., and Knight, G. J., British fournal of Venereal Diseases,

1967, 43, 16i. $1970,46,31$.

o Oates, J. K., British Medical fournal, 1971, 3, 580.

\section{Transport to the Surgery}

Home visits take more time than surgery consultations, so that bringing patients to the surgery makes sense. A few G.P.'s already run private transport and one report in 1968 from an urban practice ${ }^{1}$ suggested that providing a car service for patients benefited them by giving earlier consultation and treatment. The chronic sick and convalescent patients were helped to quicker recovery, the doctors saved time and effort and were more available for consultation, the report claimed. Could transport arrangements be generally introduced and would they be acceptable to patients?

The Institute for Social Studies in Medical Care, financed by the Department of Health and Social Security and the Scottish Home and Health Department, mounted an experiment to answer these questions in four general practices. ${ }^{2}$ All had appointment systems but were otherwise different. One with four doctors and three part-time assistants was in greater London, a single-handed practice and a group of six in a health centre were in a Welsh industrial valley, and the fourth was a single-handed practice in a widespread Scottish rural area. Visiting patterns were analysed before the service started and after it had been running for six months. The changes were compared with those in four control practices, which would reflect the current reduction in home visiting, and with that in a three-partner London practice which had run its own transport service for two years.

The changes reflected both the geographical area and the attitudes of doctors and staff. The Scottish rural practice offered transport only to one tenth of those asking for home visits and nearly all accepted it, while the other three offered the service to half, of which accepted it. Home visits decreased in both experimental and control practices but much more in those with transport, where there was a reduction in the ratio of home visits to surgery consultations. This saved time in three of them but in the single-handed Welsh practice the proportion of time spent travelling went up though fewer patients were visited.

Most patients liked the idea of trying a transport service and its introduction allayed the fears of the few who had had reservations. It enhanced their liking for their doctor as a person and for his conscientiousness. The survey revealed unmet medical needs in elderly people. Many admitted to such symptoms as difficulties in hearing, seeing, or reading, breathlessness, stiffness, or dizziness which they had not mentioned to their doctor even when they had recently consulted him about something else. This suggests that old people might benefit from regular medical examinations. Many did not know about existing chiropody services and old people's clubs and only half of those who had help at home got it through the home help service.

The main disadvantage of the service was its cost. Capital outlay was about $£ 1,000$, with an extra $£ 350$ to $£ 450$ for radio telephone equipment, and running costs varied from $£ 700$ per annum for a part-time to $£ 1,600$ for a full-time service, enough to cause two of the practices to stop it when 
the Departmental subsidy ended in the third year. This shows that before transport to the surgery could be widely introduced the health departments would have to consider reducing capital and running costs to the practices by partial reimbursement, as they already do for the salaries of the ancillary staff.

Minor disadvantages included longer consulting hours, which some doctors disliked, extra pressure on the switchboard, and patients having to wait about at home and in the surgery for transport, though it was the doctors rather than the patients who noted the last mentioned. The service did not cause ethical complications by attracting patients from nearby practices without transport. There was some evidence, however, that decreased home visiting might have made doctors less aware of their patients' social needs.

In 1967 the B.M.A. asked the Government to review urgently the "whole problem of transporting ambulant patients to doctors' surgeries" 3 and was told that research into the problem was being planned. Now that the results of this study are available, the Government and profession should decide whether a really large scale experiment is justified. This report suggests that it is.

\footnotetext{
1 Floyd, C. B., British Medical fournal, 1965, 3, 614.

2 Lance, Hilary, "Report on Transport Services in General Practice," Fournal of the Royal College of General Practitioners, 1971, .
}

3 British Medical fournal Supplement, 1967, 3, 57.

\section{Cardiofacial Syndrome}

An association between congenital heart disease and unilateral partial lower facial weakness was first observed in five infants by G. G. Cayler in $1966 .^{1}$ Nine more cases were described by Cayler ${ }^{2}$ in 1969, and in the three in which chromosome studies were made "breaks" or "deletions" were noted in half of the cells photographed. Since that time 30 cases of this unusual association have been described, and the findings are reviewed by Cayler, C. M. Blumenfeld, and R. L. Anderson. ${ }^{3}$

The main components of what is now known as the cardiofacial syndrome are congenital heart disease of widely varying type-the most common being ventricular septal defect (about 30\%), patent ductus arteriosus (about 20\%), and Fallot's tetralogy (about 16\%)-and a partial lower facial weakness which is unilateral and mainly affects the quadratus labii inferioris and mentalis muscles. The facial weakness may be transient but is usually persistent and may be so mild as to be noticeable only when the child is crying. The facies is not particularly characteristic except for the facial weakness. Among other widespread anomalies described (but none consistently) are single umbilical artery, aplasia of the radius, umbilical hernia, anal atresia, club feet, microcephaly, and renal aplasia. Six of the 30 patients had mental retardation and three had convulsions. There was no connexion with parental age, and neither pregnancy nor family histories seemed relevant. Only six of the patients had been delivered by forceps. Transient facial paresis is well known in the neonatal period and is not uncommon. ${ }^{4}$ Nevertheless, Cayler and his colleagues think that a lower facial paresis should always be carefully looked for in the newborn because of the severity of congenital heart disease in the cardiofacial syndrome. In their experience $5-10 \%$ of babies with congenital heart disease may have partial lower facial weakness.
The aetiology of the syndrome is still obscure. Viral studies are generally unhelpful, though one patient was shown to have the postrubella syndrome. It used to be thought that a subclinical infection around the fifth week of gestation could be the cause, but it now seems probable that there are diverse causes. Chromosome breaks or deletions were once thought to be characteristic of the syndrome, but Cayler and his colleagues compared the chromosomes of patients with cardiofacial syndrome with those of patients with ordinary congenital heart disease, and there was no appreciable difference in the number of breaks or deletions. Nevertheless, no comparison was made with a group of normal infants. There are no definite signs of the cardiofacial syndrome other than congenital heart disease and unilateral partial lower facial weakness, and the reason for the association remains obscure.

1 Cayler, G. G., Pediatrics, 1967, 40, 666.

2 Cayler, G. G., Archives of Disease in Childhood, 1969, 44, 69

3 Cayler, G. G., Blumenfeld, C. M., and Anderson, R. L., Chest, 1971, 60, 161.

${ }^{4}$ Hepner, W. R., Pediatrics, 1951, 8, 494.

\section{Forms of Colitis}

Early in this century non-specific ulcerative colitis was distinguished from dysentery. In 1952 it was first emphasized that the colon alone could be the site of the inflammatory process first described as regional ileitis by Crohn and his colleagues. ${ }^{1}$ In the past decade ischaemic colitis has gained recognition as a third type of non-infective colitis. ${ }^{2}$ The differential diagnosis between these three forms of nonspecific colitis can be difficult and the relationship between ulcerative colitis and colonic Crohn's disease has been the subject of much controversy. ${ }^{3-5}$ It is not known whether these are two separate diseases which sometimes simulate one another very closely or whether these types of colitis represent different reactions of the body to one aetiological agent. This problem will only be resolved when their aetiology is known. In the meantime the definition of these disorders rests on an overall assessment of their clinical, radiological, and pathological features.

That some patients with non-specific colitis cannot easily be fitted into one of these three categories has recently been emphasized by W. T. Miller and his co-workers. ${ }^{6}$ They describe five patients (two male and three female, none on oral contraceptives) who were aged from 19 to 42 years and who presented with a brief history of abdominal cramps and diarrhoea. Three of the patients passed blood with the motions, and in one of them rectal bleeding was the first symptom. The rectal mucosa appeared normal on proctoscopy except in one patient, in whom a few haemorrhages were noted. Barium enema showed disease of the right colon in two patients, the transverse colon in one, and skip areas in another two with spasm, "thumbprinting" appearances, or ulceration in the diseased parts. In all but one case the small bowel was visualized and appeared normal. Examination of the stool in three patients showed no intestinal pathogens. Only one rectal biopsy was performed, and the specimen was normal. Treatment was symptomatic except for one patient who was given sulphasalazine, and in all five the symptoms resolved within two weeks of their onset. Repeat barium studies between three weeks and six months later were normal, and there was no relapse in a follow-up period lasting from one to four years. The authors suggest that the clinico- 